\title{
Photoluminescence of $\mathrm{Nd}$-doped $\mathrm{SnO}_{2}$ thin films
}

H. Rinnert, P. Miska, M. Vergnat, G. Schmerber, S. Colis, A. Dinia, D. Muller, G. Ferblantier, and A. Slaoui

Citation: Appl. Phys. Lett. 100, 101908 (2012); doi: 10.1063/1.3692747

View online: https://doi.org/10.1063/1.3692747

View Table of Contents: http://aip.scitation.org/toc/apl/100/10

Published by the American Institute of Physics

\section{Articles you may be interested in}

Structural and photoluminescence properties of tin oxide and tin oxide: C core-shell and alloy nanoparticles synthesised using gas phase technique

AlP Advances 6, 095321 (2016); 10.1063/1.4964313

Structural and optical properties of $\mathrm{Cu}$ doped $\mathrm{SnO}_{2}$ nanoparticles: An experimental and density functional study Journal of Applied Physics 113, 233514 (2013); 10.1063/1.4811374

Role of donor-acceptor complexes and impurity band in stabilizing ferromagnetic order in $\mathrm{Cu}$-doped $\mathrm{SnO}_{2}$ thin films

Applied Physics Letters 100, 172402 (2012); 10.1063/1.4705419

Oxygen-vacancy and depth-dependent violet double-peak photoluminescence from ultrathin cuboid $\mathrm{SnO}_{2}$ nanocrystals

Applied Physics Letters 100, 121903 (2012); 10.1063/1.3696044

Ferromagnetism in Fe-doped $\mathrm{SnO}_{2}$ thin films

Applied Physics Letters 84, 1332 (2004); 10.1063/1.1650041

Photoluminescence in quantum-confined $\mathrm{SnO}_{2}$ nanocrystals: Evidence of free exciton decay

Applied Physics Letters 84, 1745 (2004); 10.1063/1.1655693

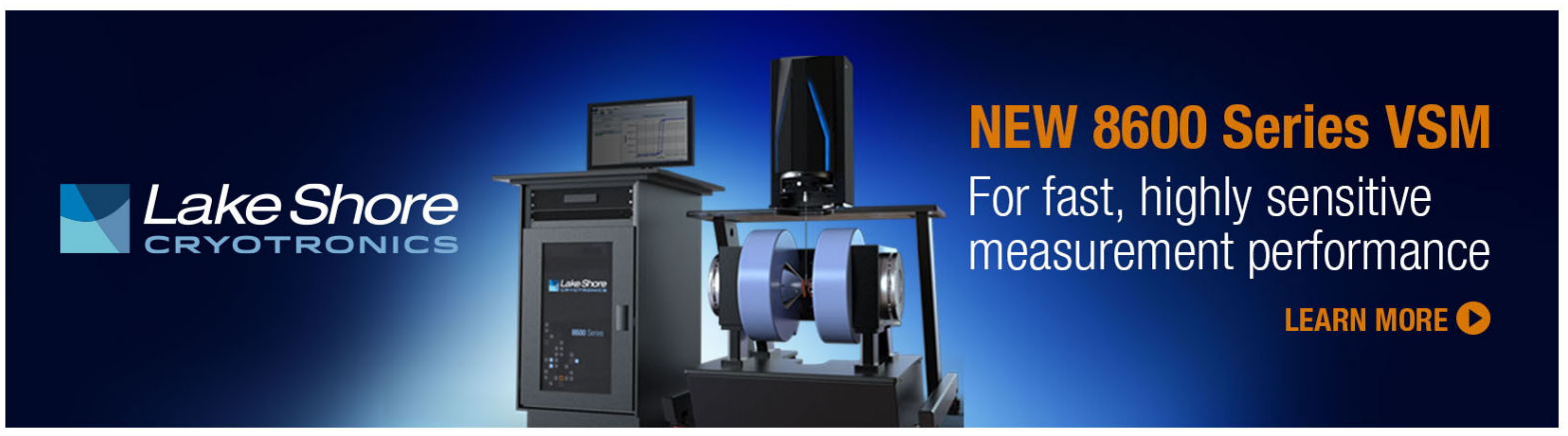




\title{
Photoluminescence of $\mathrm{Nd}$-doped $\mathrm{SnO}_{2}$ thin films
}

\author{
H. Rinnert, ${ }^{1, a)}$ P. Miska, ${ }^{1}$ M. Vergnat, ${ }^{1}$ G. Schmerber, ${ }^{2}$ S. Colis, ${ }^{2}$ A. Dinia,${ }^{2}$ D. Muller, ${ }^{3}$ \\ G. Ferblantier, ${ }^{3}$ and A. Slaoui ${ }^{3}$ \\ ${ }^{1}$ IJL, UMR CNRS 7198, Université de Lorraine, Boulevard des Aiguillettes, B.P. 70239, 54506 \\ Vandœuvre-lès-Nancy, France \\ ${ }^{2}$ IPCMS, UMR CNRS 7504 UDS-ECPM, 23 rue du Loess, B.P. 43, 67034 Strasbourg, France \\ ${ }^{3}$ InESS, UMR CNRS 7163 UDS, 23 rue du Loess, B.P. 43, 67037 Strasbourg, France
}

(Received 16 December 2011; accepted 21 February 2012; published online 8 March 2012)

\begin{abstract}
Structural, optical, and electrical properties of $\mathrm{Nd}$-doped $\mathrm{SnO}_{\mathrm{x}}$ thin films are reported. The atomic structure was characterized by $\mathrm{x}$-ray diffraction and infrared absorption spectrometry. Investigation of the photoluminescence properties revealed Nd-related bands at 920 and $1100 \mathrm{~nm}$ for samples annealed at $700{ }^{\circ} \mathrm{C}$, which present the tetragonal structure of the $\mathrm{SnO}_{2}$ rutile phase. $\mathrm{Nd}^{3+}$ ions can be indirectly excited and no concentration quenching was observed up to 3 at. \%. It is concluded that $\mathrm{Nd}^{3+}$ ions are efficient optically active dopants in addition to be responsible of the observed electric conductivity improvement. These materials are then interesting for solar cell applications. (C) 2012 American Institute of Physics. [http://dx.doi.org/10.1063/1.3692747]
\end{abstract}

Transparent and conductive oxide (TCO) layers have attracted considerable attention because of their optical transmittance in the visible range and their excellent electrical properties. These materials are often used as efficient transparent electrodes for applications such as solar cells or flat panel displays. Doping with extrinsic impurities is generally performed to improve the conductivity. Fluorine-doped $\mathrm{SnO}_{2}$ is, for example, one of the most popular TCO layer. ${ }^{1,2}$ On the other hand, the use of impurities like rare earth (RE) ions can give rise to light emission properties at wavelengths from the far-infrared to the ultraviolet spectral range. The light emission from the RE generally arises from intrashell transitions of $4 f$ electrons which are, in first order, electric dipole forbidden. Hence, a resonant excitation of the RE leads to a weak luminescence efficiency. However, an indirect excitation mechanism can lead to a strong increase of the excitation efficiency of the optically active ions. Energy transfer processes from the matrix to the ions can induce an indirect excitation of RE ions. ${ }^{3}$ For instance, a three orders of magnitude increase of the $\mathrm{Er}^{3+}$ excitation cross section has been demonstrated in Er-doped $\mathrm{SiO}_{\mathrm{x}}$ thin films because of an efficient energy transfer process from silicon nanocrystals to the ions. ${ }^{4}$ From the application side, RE doped materials are potentially very good candidates for photonic conversion layers towards the increase of the solar cell efficiency. Indeed, the thermalization of high energy photons in most solar cells is an important loss and could be strongly reduced by the down conversion (DC) process. In practice, the down conversion can be performed by the absorption of one photon by a host matrix followed by an energy transfer to two rare earth ions which emit light at lower energy. ${ }^{5,6}$

In this letter, we report a study dedicated to the Ndrelated luminescence in a $\mathrm{SnO}_{\mathrm{x}}$ host matrix. Such Nd-doped $\mathrm{SnO}_{\mathrm{x}}$ combines both semiconducting and optical properties and can serve as a DC converter. Indeed, $\mathrm{Nd}^{3+}$ ions present several technologically important luminescent bands including

\footnotetext{
${ }^{\text {a) }}$ Author to whom correspondence should be addressed. Electronic mail: herve.rinnert@ijl.nancy-universite.fr.
}

the ${ }^{4} \mathrm{~F}_{3 / 2} \rightarrow{ }^{4} \mathrm{I}_{11 / 2},{ }^{4} \mathrm{~F}_{3 / 2} \rightarrow{ }^{4} \mathrm{I}_{9 / 2}$, and ${ }^{4} \mathrm{~F}_{3 / 2} \rightarrow{ }^{4} \mathrm{I}_{13 / 2}$ 4f-shell transitions which are, respectively, the basis of $1.05 \mu \mathrm{m} \mathrm{Nd}$ lasers, a second lasing transition at $900 \mathrm{~nm}$, and a $1.3-1.4 \mu \mathrm{m}$ band in the second fiber transparency window. The transitions at $900 \mathrm{~nm}$ and $1 \mu \mathrm{m}$ also render $\mathrm{Nd}^{3+}$ ions of particular interest for silicon based solar cells. These emission energies are slightly greater than the silicon bandgap energy and the $\mathrm{Nd}$ emission could, therefore, efficiently contribute in creating a photocurrent. Thus, the Nd-doped $\mathrm{SnO}_{\mathrm{x}}$ layers are promising materials for the down-conversion, allowing the photonic conversion of ultraviolet photons to near infrared ones.

$\mathrm{SnO}_{2}$ powder was evaporated from an electron beam gun in a high-vacuum chamber with a base pressure of $1 \times 10^{-8}$ mbar. During evaporation, a partial decomposition of the $\mathrm{SnO}_{2}$ source occurred and the pressure increased until $6 \times 10^{-6}$ mbar. The silicon substrates were maintained at $100^{\circ} \mathrm{C}$. The deposition rate was controlled by a quartz microbalance and was equal to $0.1 \mathrm{~nm} / \mathrm{s}$. The layer thickness was $200 \mathrm{~nm}$ for all samples. The in-situ Nd doping was performed from an effusion cell. The determination of the $\mathrm{Nd}$ content, defined by $\mathrm{C}_{\mathrm{Nd}}=[\mathrm{Nd}] /([\mathrm{Sn}]+2[\mathrm{O}]+[\mathrm{Nd}])$, was obtained by Rutherford backscattering spectrometry (RBS) and energy dispersive $\mathrm{x}$-ray spectroscopy (EDXS). As the as-deposited samples were sub-stoichiometric, they were annealed in a tubular oven under air for $1 \mathrm{~h}$ and at different temperatures up to $700^{\circ} \mathrm{C}$. The crystallographic structure was determined by grazing incidence $\mathrm{x}$-ray diffraction (XRD) experiments carried out with $\mathrm{Cu} \mathrm{K} \alpha(0.154 \mathrm{~nm})$ incident radiation. A germanium crystal with an incidence angle of $1^{\circ}$ was used as monochromator. The atomic bonding of the films was determined by Fourier transform infrared (FTIR) spectroscopy. The spectra were obtained in the 180$3000 \mathrm{~cm}^{-1}$ range with a resolution of $8 \mathrm{~cm}^{-1}$. The contribution of an uncoated reference silicon substrate was subtracted from the experimental spectra. For the steady state photoluminescence (PL) experiments, the samples were excited by the $325 \mathrm{~nm}$ line of a $30 \mathrm{~mW} \mathrm{He}-\mathrm{Cd}$ laser. The PL signal was analyzed by a monochromator equipped with a 600 grooves/ $\mathrm{mm}$ grating and by a photomultiplier tube cooled at $190 \mathrm{~K}$. 
The spectral response of the detection system was precisely calibrated with a tungsten wire calibration source. The electrical properties of films were studied at room temperature using an ECOPIA Hall effect measurement system.

Figure 1 shows the XRD patterns for as-deposited samples and samples annealed at different temperatures. The asdeposited sample $\left(100^{\circ} \mathrm{C}\right)$ is amorphous, as demonstrated by the very large peak around $30^{\circ}$. For annealing temperatures of 300 and $500^{\circ} \mathrm{C}$, the spectra show numerous narrow peaks which correspond to the tetragonal $\mathrm{SnO}$ phase. When the annealing temperature is raised at $700^{\circ} \mathrm{C}$, the XRD results show the expected reflections from the tetragonal structure of the $\mathrm{SnO}_{2}$ rutile-type cassiterite phase. These results are in agreement with those of Pan et al. ${ }^{7,8}$ who reported that amorphous films were obtained when deposited at substrate temperatures below $300^{\circ} \mathrm{C}$, while films grown above $350{ }^{\circ} \mathrm{C}$ have a crystalline $\alpha$-SnO structure. The structure of these films fully changes to the rutile phase when annealed at temperatures above $600^{\circ} \mathrm{C}$. The intensity ratios between the peaks are in agreement with those expected in polycrystal ${ }^{9}$ suggesting the absence of the texture in the films. Moreover, the diffraction patterns did not show any peak corresponding to $\mathrm{Nd}$ or its compounds.

Figure 2 shows the infrared absorption spectra for the as-deposited sample and the samples annealed at different temperatures. As there is no peak in the high wavenumber range, only the spectra in the $180-700 \mathrm{~cm}^{-1}$ range are presented. The as-deposited sample, which has an amorphous structure, shows a large peak around $420 \mathrm{~cm}^{-1}$ with a full width at half maximum (FWHM) equal to $100 \mathrm{~cm}^{-1}$. This band could be related to amorphous phase of $\mathrm{SnO}_{\mathrm{x}}$ with oxygen vacancy. ${ }^{10}$ The samples annealed at 300 and $500^{\circ} \mathrm{C}$ have the $\mathrm{SnO}$ structure and present a peak at $260 \mathrm{~cm}^{-1}$ with a FWHM of about $50 \mathrm{~cm}^{-1}$. For the sample annealed at $700^{\circ} \mathrm{C}$ which has the rutile-type structure of $\mathrm{SnO}_{2}$, this peak deconvolutes into two peaks at 244 and $293 \mathrm{~cm}^{-1}$ and other peaks appear at 467,560 , and $607 \mathrm{~cm}^{-1}$. As explained by Hirata et al., ${ }^{11}$ the peaks at 244,293 , and $607 \mathrm{~cm}^{-1}$ correspond to $\mathrm{E}_{\mathrm{u}}$ modes and the peak at $477 \mathrm{~cm}^{-1}$ corresponds to

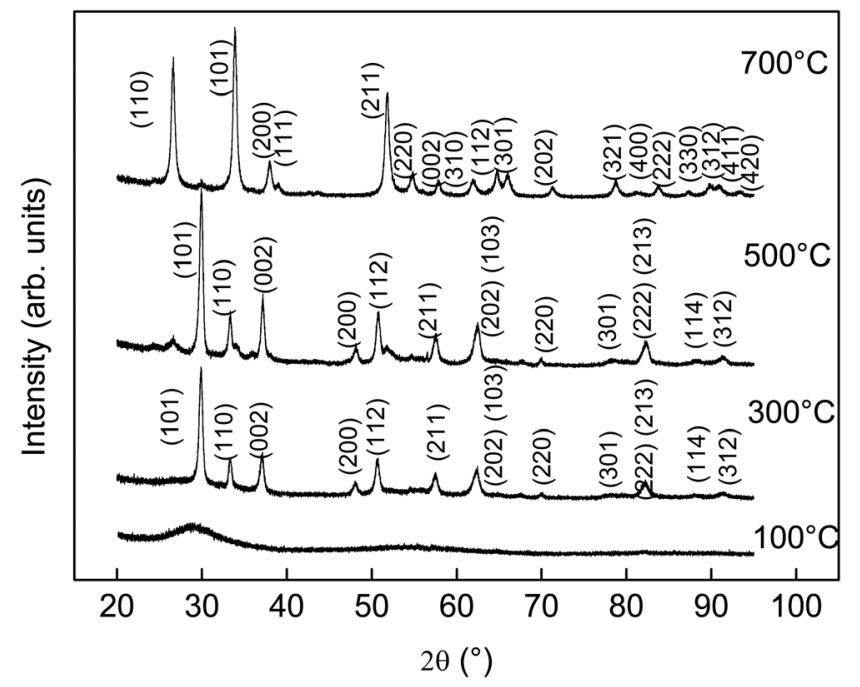

FIG. 1. X-ray diffraction patterns of $\mathrm{SnO}_{\mathrm{x}}$ films versus annealing temperature. The peak assignment is for $\mathrm{SnO}_{2}$ for the top spectrum and $\mathrm{SnO}$ for the other spectra.

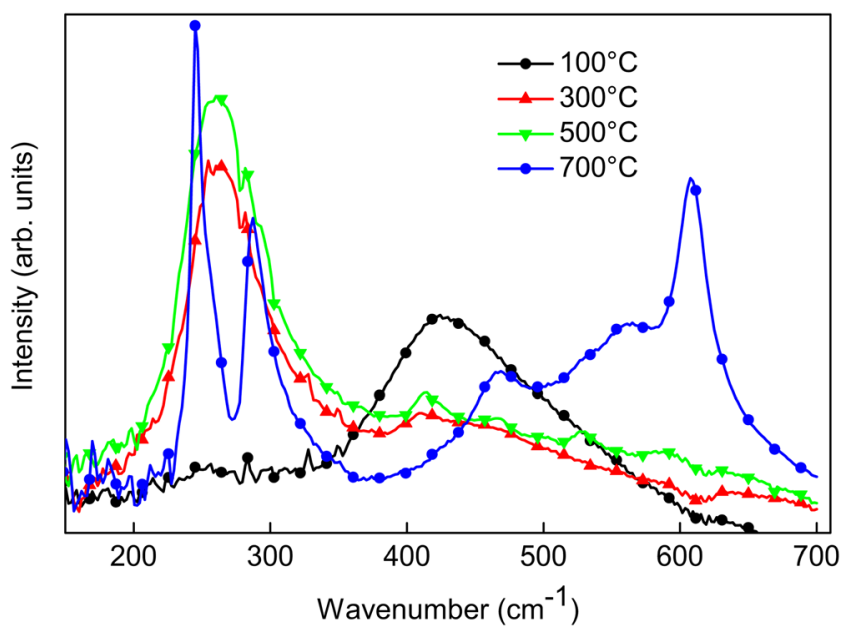

FIG. 2. (Color online) Infrared absorption spectra of $\mathrm{SnO}_{\mathrm{x}}$ films versus annealing temperature.

$\mathrm{A}_{2 \mathrm{u}}$ modes in $\mathrm{SnO}_{2}$. The origin of the peak at $560 \mathrm{~cm}^{-1}$ is still unclear but has been attributed in literature to surface vibration modes. ${ }^{12}$

The room temperature PL spectra for samples annealed at $700{ }^{\circ} \mathrm{C}$ in air and having different $\mathrm{Nd}$ concentrations are presented in Fig. 3. The inset of this figure shows the PL for the sample doped with 1.6 at. \% $\mathrm{Nd}$ and for different annealing temperatures. The as-deposited sample and those annealed at 300 and $500^{\circ} \mathrm{C}$ do not show any Nd-related PL signal. For the samples annealed at $700^{\circ} \mathrm{C}$, the characteristic PL emissions of $\mathrm{Nd}^{3+}$ ions are obtained. Emissions at 920, 1100 , and $1300 \mathrm{~nm}$ are due to transitions from the ${ }^{4} F_{3 / 2}$ excited state to the ${ }^{4} I_{\mathrm{n} / 2}$ levels with $\mathrm{n}$ equal to 13,11 , and 9 , respectively. The intensity of these bands increases with the $\mathrm{Nd}$ content in the $\mathrm{SnO}_{\mathrm{x}}$ matrix up to a $\mathrm{Nd}$ concentration equal to 3 at. \%. For higher doping level, the PL intensity decreases. This effect could be attributed to a concentration quenching effect characterized by the energy exchange between a pair of $\mathrm{Nd}$ ions. This nonradiative process is generally described by a cross-relaxation process in which two neighboring ions are exchanging energy and by the

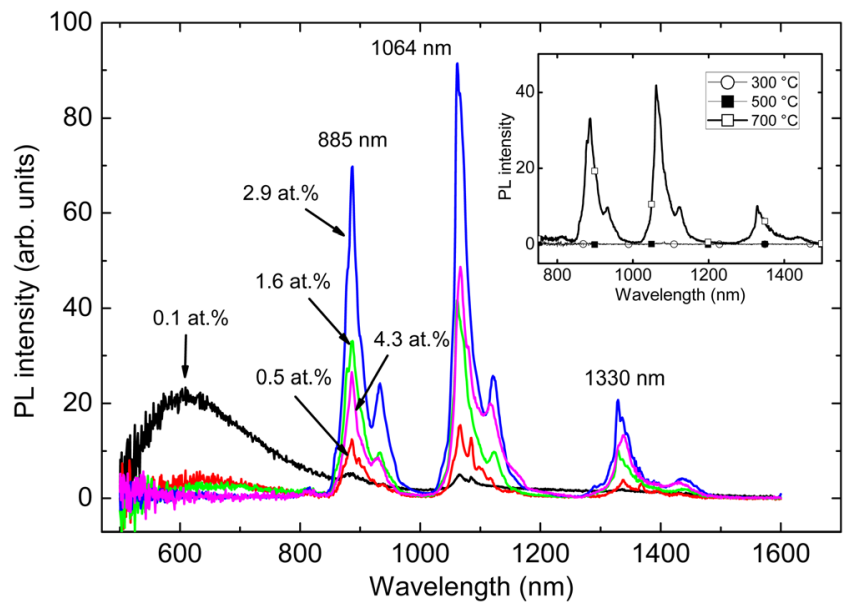

FIG. 3. (Color online) Room-temperature PL spectra of Nd-doped $\mathrm{SnO}_{\mathrm{x}}$ alloys annealed at $700{ }^{\circ} \mathrm{C}$, for different $\mathrm{Nd}$ concentrations. The inset shows the influence of annealing temperature on the PL for $\mathrm{Nd}$ concentration equal to 1.6 at. $\%$. 
migration of the excitation energy, as demonstrated in Nddoped phosphate glasses or silica glasses. ${ }^{13,14}$ Moreover, a decrease of the PL intensity due to the solubility limit of $\mathrm{Nd}$ in $\mathrm{SnO}_{2}$ cannot be rejected. The evolution of the PL spectra with the doping level is also correlated to the PL band at around $600 \mathrm{~nm}$. For the sample doped with 0.1 at. $\mathrm{Nd} \%$, the intensity of this contribution is high while the Nd-related peaks are hardly visible. For higher Nd contents, the intensity of this peak is a decreasing function of the $\mathrm{Nd}$ content. The origin of this PL band is not clear but could be due to radiative transition between electronic states originating from defects in the $\mathrm{SnO}_{2}$ bandgap. As the excitation wavelength used for the PL measurements is equal to $325 \mathrm{~nm}$, the excitation of the $\mathrm{Nd}^{3+}$ ions probably occurs via indirect mechanisms like carrier-mediated processes. An energy transfer process between defect states giving rise to the luminescence at around $600 \mathrm{~nm}$ and the $\mathrm{Nd}^{3+}$ ions could be such a process. Indeed the energy value between the ground state and the ${ }^{4} G_{5 / 2},{ }^{2} G_{7 / 2}$ excited states is equal to $590 \mathrm{~nm}$. Such an energy transfer process could explain the simultaneous decrease of the wide PL band and the increase of the Ndrelated ones.

The evolution of the PL properties with the annealing treatments also suggests that the $\mathrm{SnO}_{2}$ chemical composition and the rutile structure are needed to optically activate the $\mathrm{Nd}^{3+}$ ions. It is known that the electric dipole transition between intra $4 f$ states are forbidden for isolated rare earth ions. The crystal field can, however, contribute to relax this selection rule by mixing states from different parities. ${ }^{15}$ The optical activity of the RE ions is then strongly dependent on the magnitude of the crystal field which in turn depends on the symmetry of the occupied site and on the Nd-ligand bonds. Ionic Nd-ligand bonds are assumed to strength the coupling to the lattice and then favour the luminescence. Oxygen atoms are then good candidates to increase the optical activation of $\mathrm{Nd}^{3+}$ ions, which could explain the strong PL for the sample annealed at $700^{\circ} \mathrm{C}$.

The modification of the electric properties induced by $\mathrm{Nd}$ doping was also investigated in this work. Thus the carrier concentration $\mathrm{n}$, the Hall mobility $\mu$, and the electrical resistivity $\rho$ were measured at room temperature using the Van der Pauw method. ${ }^{16}$ Such data are of great importance and show the potential interest of $\mathrm{SnO}_{\mathrm{x}}$ : $\mathrm{Nd}$ layers for photovoltaic applications. Indeed, in such cases, the layers should have high electrical conductivity to allow the collection of the photogenerated carriers. For as-deposited samples, the conductivity is too weak to allow the measurements of their transport properties. Table I gives the values of carrier concentration, resistivity, and Hall mobility for the $\mathrm{SnO}_{2}: \mathrm{Nd}$ samples annealed at $700{ }^{\circ} \mathrm{C}$ and containing different $\mathrm{Nd}$ concentrations. All $\mathrm{SnO}_{2}$ : Nd thin films are found to be n-type conducting. This is expected as $\mathrm{SnO}_{\mathrm{x}}$ layers are known to be n-type semiconductors because of intrinsic donors such as lattice defects or oxygen vacancies. Thus, our results show that the conduction type is not changed upon $\mathrm{Nd}$ doping. As the $\mathrm{Nd}$ concentration increases from 0.1 to 2.9 at. \%, the free carrier concentration increased from $2 \times 10^{19}$ up to
TABLE I. Values of carrier concentration, resistivity, and Hall mobility for $\mathrm{SnO}_{2}$ : Nd samples annealed at $700^{\circ} \mathrm{C}$, for different $\mathrm{Nd}$ concentrations.

\begin{tabular}{lccc}
\hline \hline $\begin{array}{c}\mathrm{Nd} \text { content } \\
(\text { at. \% })\end{array}$ & $\begin{array}{c}\text { Carrier } \\
\text { concentration } \\
\left(\mathrm{cm}^{-3}\right)\end{array}$ & $\begin{array}{c}\text { Resistivity } \\
(\mathrm{ohm} \mathrm{cm})\end{array}$ & $\begin{array}{c}\text { Mobility } \\
\left(\mathrm{cm}^{2} / \mathrm{Vs}\right)\end{array}$ \\
\hline 0.1 & $-2.4 \times 10^{19}$ & 0.3 & 0.8 \\
0.5 & $-3 \times 10^{20}$ & 0.033 & 0.7 \\
1.6 & $-2.5 \times 10^{21}$ & 0.018 & 0.17 \\
2.9 & $-1.5 \times 10^{21}$ & 0.033 & 0.15 \\
\hline \hline
\end{tabular}

$2.5 \times 10^{21} \mathrm{~cm}^{-3}$, while the Hall mobility is found to decrease. Such decrease could be attributed to the structural disorder, grain boundaries, and/or to ionized impurity scattering, as already suggested by Thangaraju. ${ }^{17}$ As the mobility decrease is weaker than the carrier concentration increase, the resistivity decreases with $\mathrm{Nd}$ content which improves the electrical properties of the layer. Further experiments are needed to improve the microstructure which probably limits the conductivity.

In conclusion, we have fabricated Nd-doped $\mathrm{SnO}_{2}$ layers by evaporation of $\mathrm{SnO}_{2}$ powder combined with an Nd effusion source. The $\mathrm{SnO}_{2}$ : Nd films are found to be photoluminescent upon thermal annealing. With an excitation in the UV range, most of the emitted light occurs at energies slightly above the Si bandgap. The optical activation of the $\mathrm{Nd}^{3+}$ ions is obtained, provided the sample has the $\mathrm{SnO}_{2}$ stoichiometry and the tetragonal structure of the rutile phase, which is optimized after an annealing treatment at $700^{\circ} \mathrm{C}$ in air. The $\mathrm{SnO}_{2}$ host matrix allowed to introduce $\mathrm{Nd}$ ions with a concentration as large as 3 at. \% without any concentration quenching. The electric properties are still interesting upon $\mathrm{Nd}$ doping, which suggest that these layers are of potential interest for optoelectronic applications, in particular as down-converter layers for Si-based solar cells.

${ }^{1}$ A. F. Khan, M. Mehmood, A. M. Rana, and M. T. Bhatti, Appl. Surf. Sci. 255, 8562 (2009).

${ }^{2}$ D. W. Sheel, H. M. Yates, P. Evans, U. Dagkaldiran, A. Gordijn, F. Finger, Z. Remes, and M. Vanecek, Thin Solid Films 517, 3061 (2009).

${ }^{3}$ A. J. Kenyon, Prog. Quantum Electron. 26, 225 (2002).

${ }^{4}$ A. Polman, J. Appl. Phys. 82, 1 (1997).

${ }^{5}$ T. Trupke, M. A. Green, and P. Würfel, J. Appl. Phys. 92, 1668 (2002).

${ }^{6}$ T. Trupke, M. A. Green, and P. Würfel, J. Appl. Phys. 92, 4117 (2002).

${ }^{7}$ X. Q. Pan and L. Fu, J. Appl. Phys. 89, 6048 (2001).

${ }^{8}$ X. Q. Pan and L. Fu, J. Appl. Phys. 89, 6056 (2001).

${ }^{9}$ International Center for Diffraction Database (ICDD), card number 0411445 for $\mathrm{SnO}_{2}$ and 006-0395 for $\mathrm{SnO}$.

${ }^{10}$ S. Chacko, N. S. Philip, K. G. Gopchandran, P. Koshy, and V. K. Vaidyan, Appl. Surf. Sci. 254, 2179 (2008).

${ }^{11}$ T. Hirata, K. Ishioka, M. Kitajima, and H. Doi, Phys. Rev. B 53, 8442 (1996).

${ }^{12}$ X. S. Peng, L. D. Zhang, G. W. Meng, Y. T. Tian, Y. Lin, Y. Geng, and S. H. Sun, J. Appl. Phys. 93, 1760 (2003).

${ }^{13}$ H. Ebendorff-Heidepriem, W. Seeber, and D. Ehrt, J. Non Cryst. Solids 183, 191 (1995).

${ }^{14}$ S. E. Stokowski, L. Cook, H. Mueller, and M. J. Weber, J. Lumin. 31-32, 823 (1984).

${ }^{15}$ B. R. Judd, Phys. Rev. B 127, 750 (1962)

${ }^{16}$ D. K. Schroder, Semiconductor Material and Device Characterization (Wiley, New York, 1990).

${ }^{17}$ B. Thangaraju, Thin Solid Films 402, 71 (2002). 